\title{
Das nuvens
}

Duarte Belo

drtbelo@yahoo.com

Para citação: BELO, Duarte - Das nuvens. Estudo Prévio 14. Lisboa: CEACT/UAL - Centro de Estudos de Arquitetura, Cidade e Território da Universidade Autónoma de Lisboa, 2018. ISSN: 2182-4339 [Disponível em: www.estudoprevio.net]. DOI: https://doi.org/10.26619/2182-4339/14.4

Artigo recebido a 20 de setembro de 2018 e aceite para publicação a 20 de dezembro de 2018. Creative Commons, licença CC BY-4.0: https://creativecommons.org/licenses/by/4.0/

\section{Das nuvens}

Como se vindos de um lugar desconhecido, começássemos a caminhar do alto da montanha na direção do mar. Imersos num oceano de nuvens, humidade densa, penetramos no labirinto verde, de ramagens antigas, troncos seculares. O fogo haveria de trazer novos desenhos, rubros, negros, brancos. Só mais tarde, nas cotas baixas, nos aperceberíamos da civilização.

As primeiras fotografias deste conjunto, a preto e branco, foram feitas no ano 1992. As mais recentes imagens são do corrente ano, 2018. As paisagens calcinadas foram registadas em 2016, após o grande incêndio de agosto desse ano, que se aproximou do coração do Funchal. Todas as fotografias foram feitas na ilha da Madeira.

Palavras-Chave: Madeira, incêndios, fotografia, ensaio visual, Funchal. 


\section{estudoprévio}

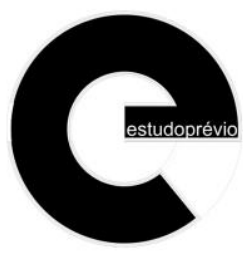

PT | P02 | EP14 | w2018
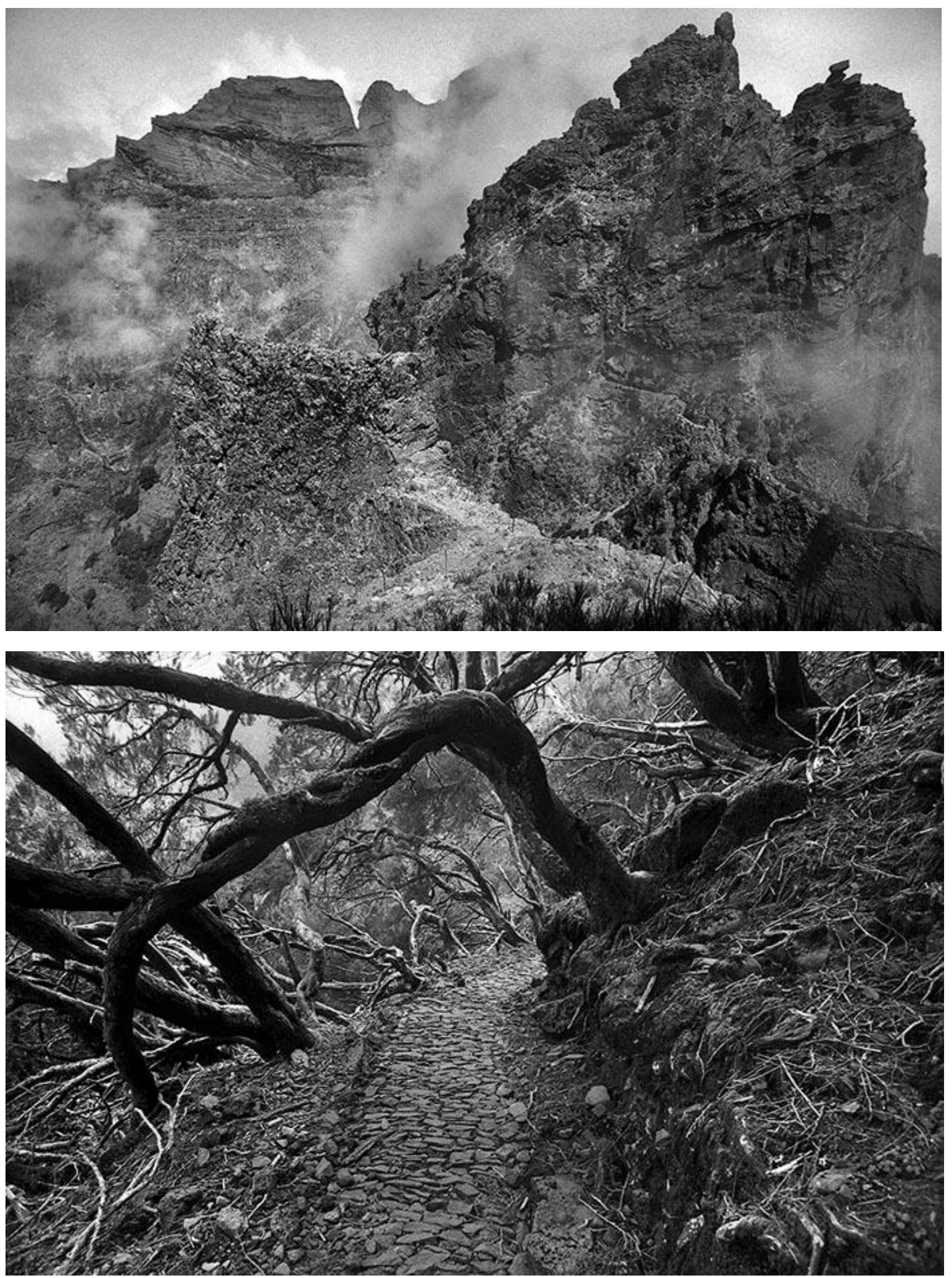


\section{estudoprévio}

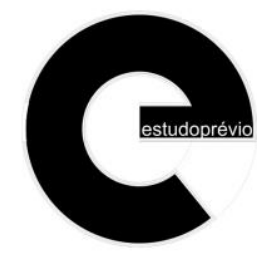

PT | P02 | EP14 | w2018
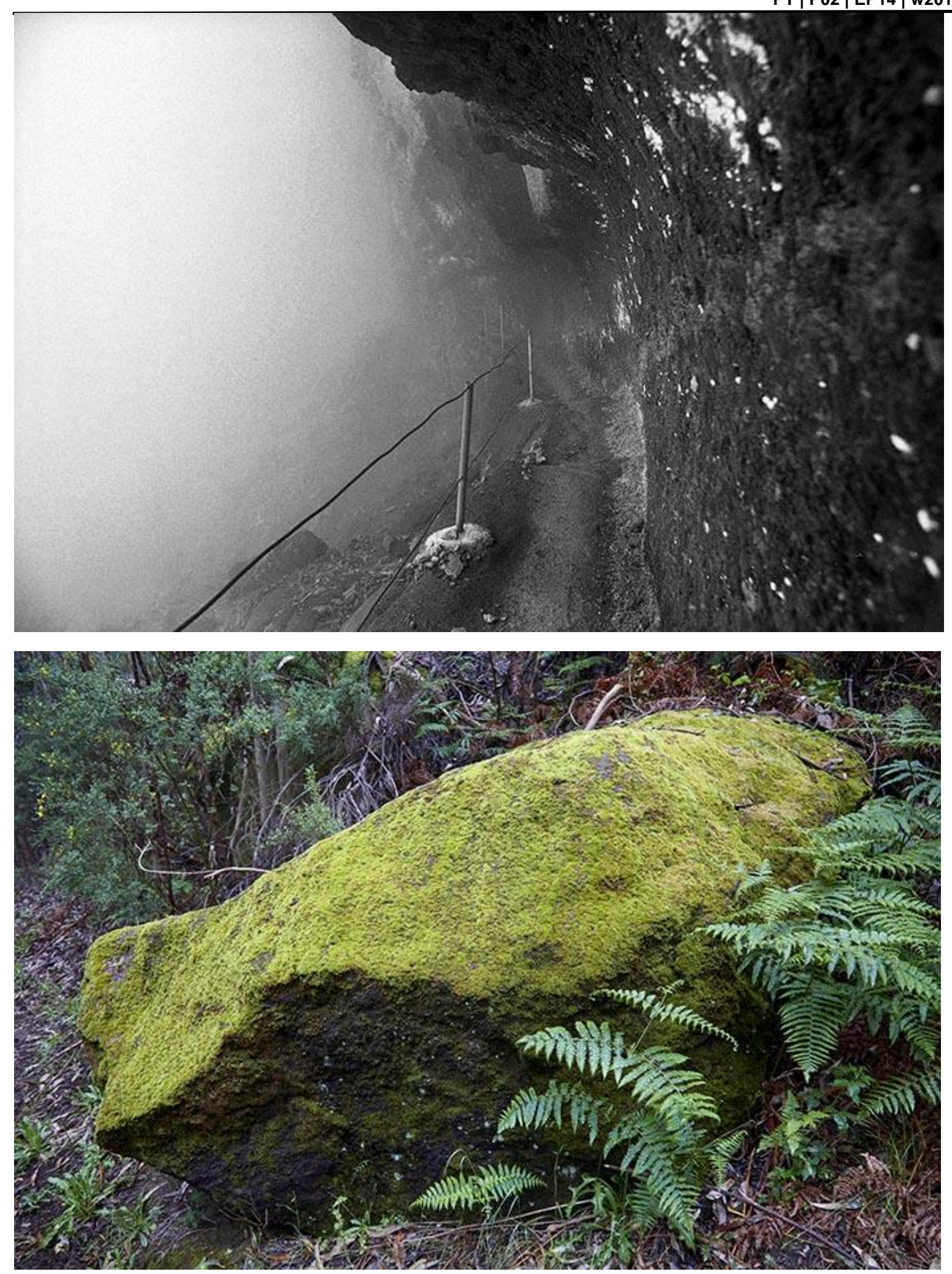
estudoprévio

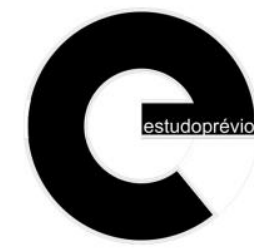

PT | P02 | EP14 | w2018
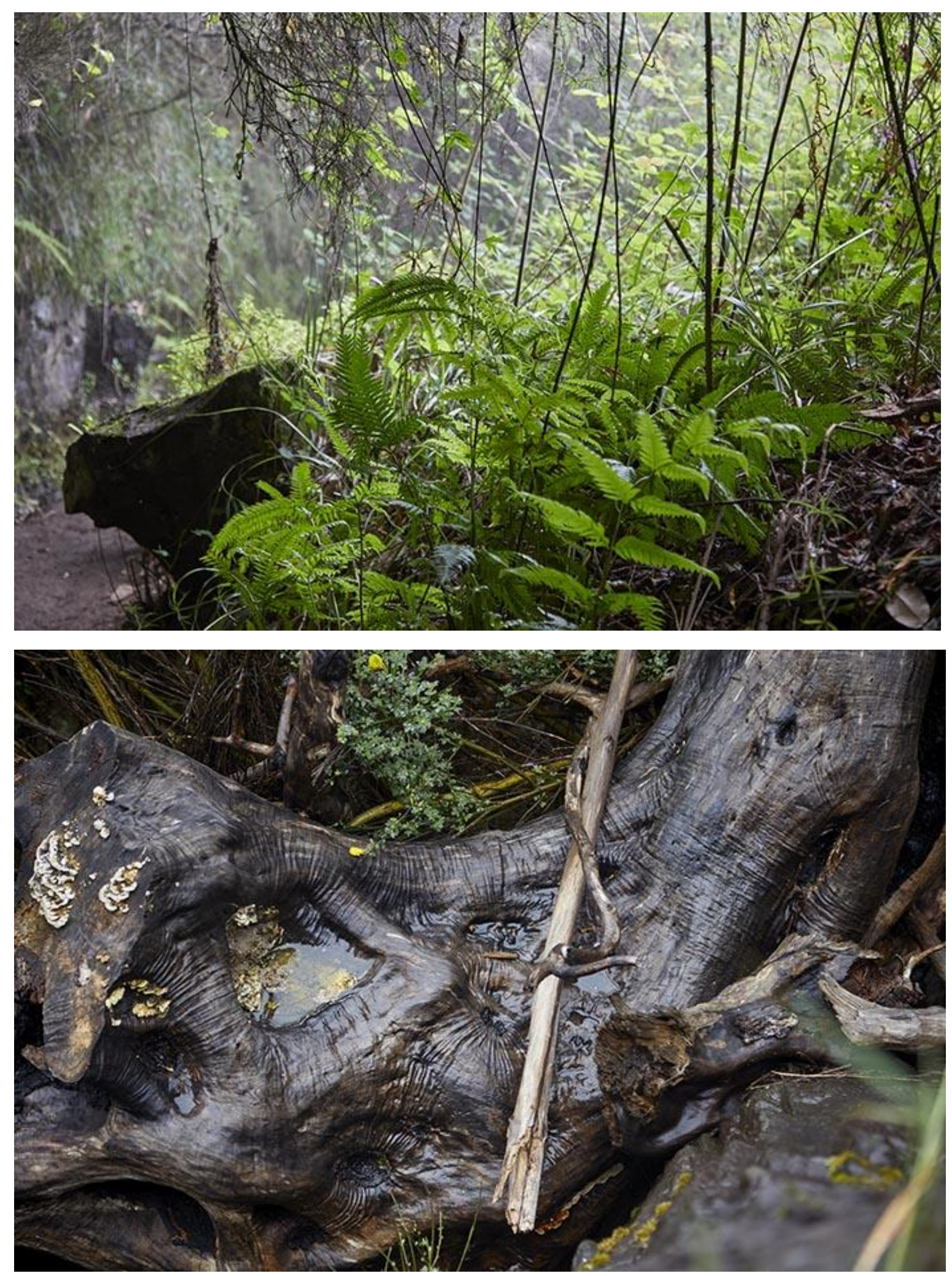


\section{estudoprévio}

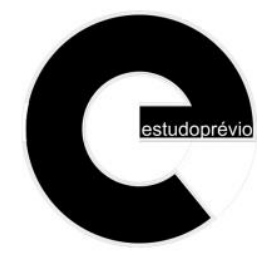

PT | P02 | EP14 | w2018
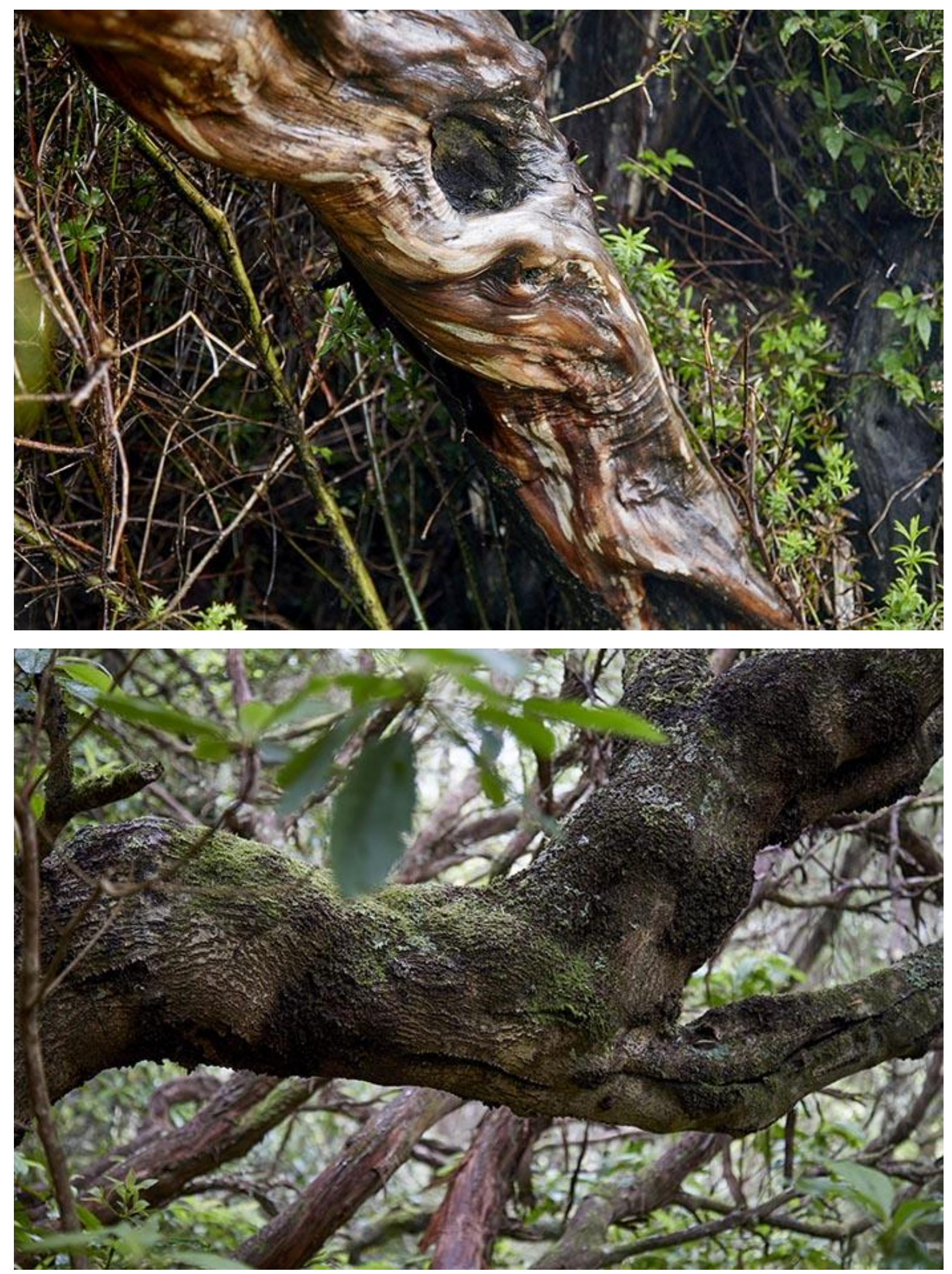


\section{estudoprévio}
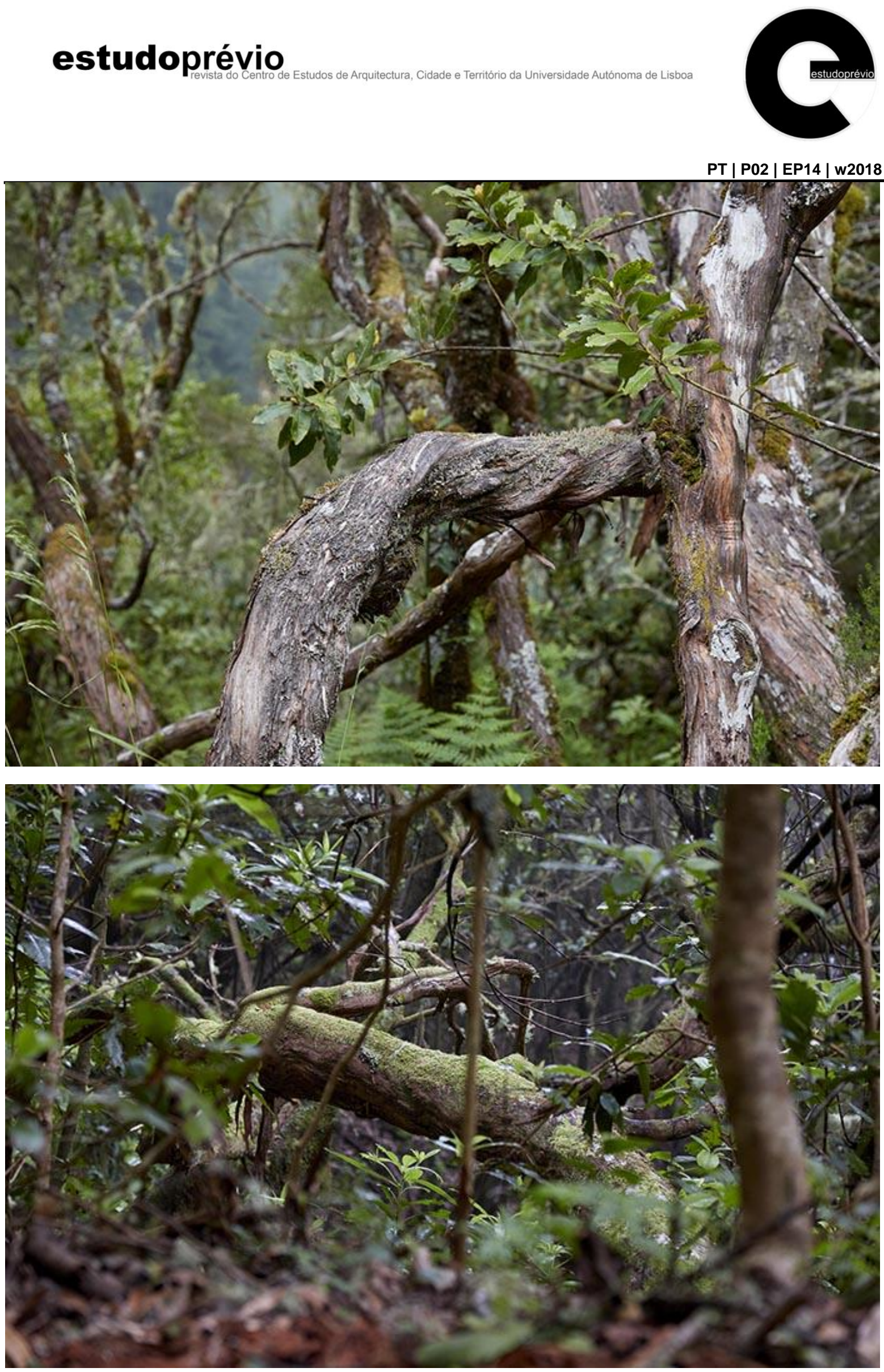


\section{estudoprévio}
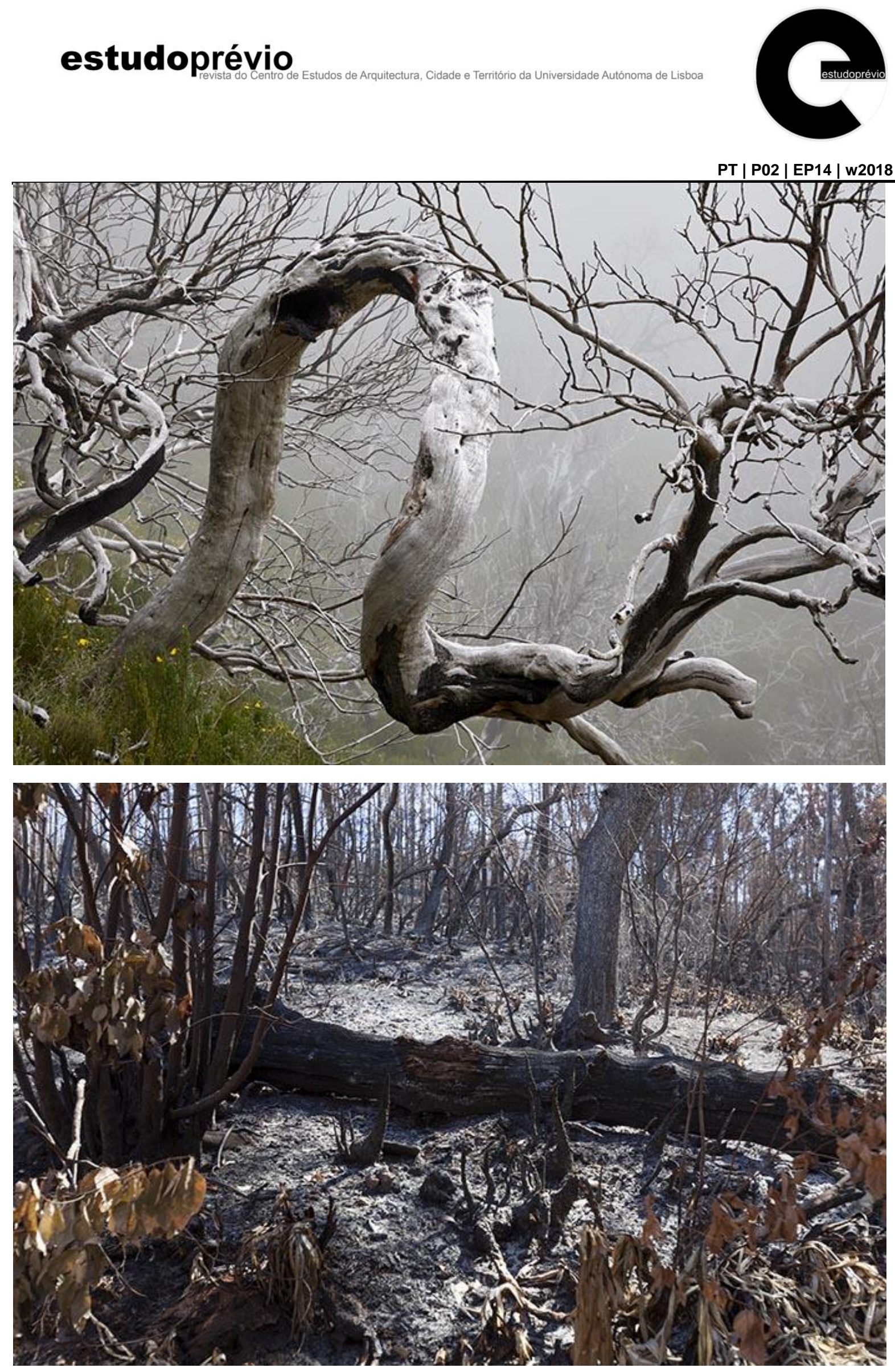


\section{estudoprévio}

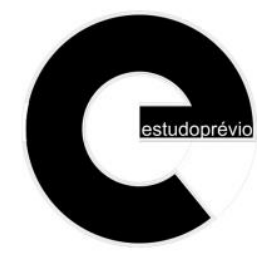

PT | P02 | EP14 | w2018
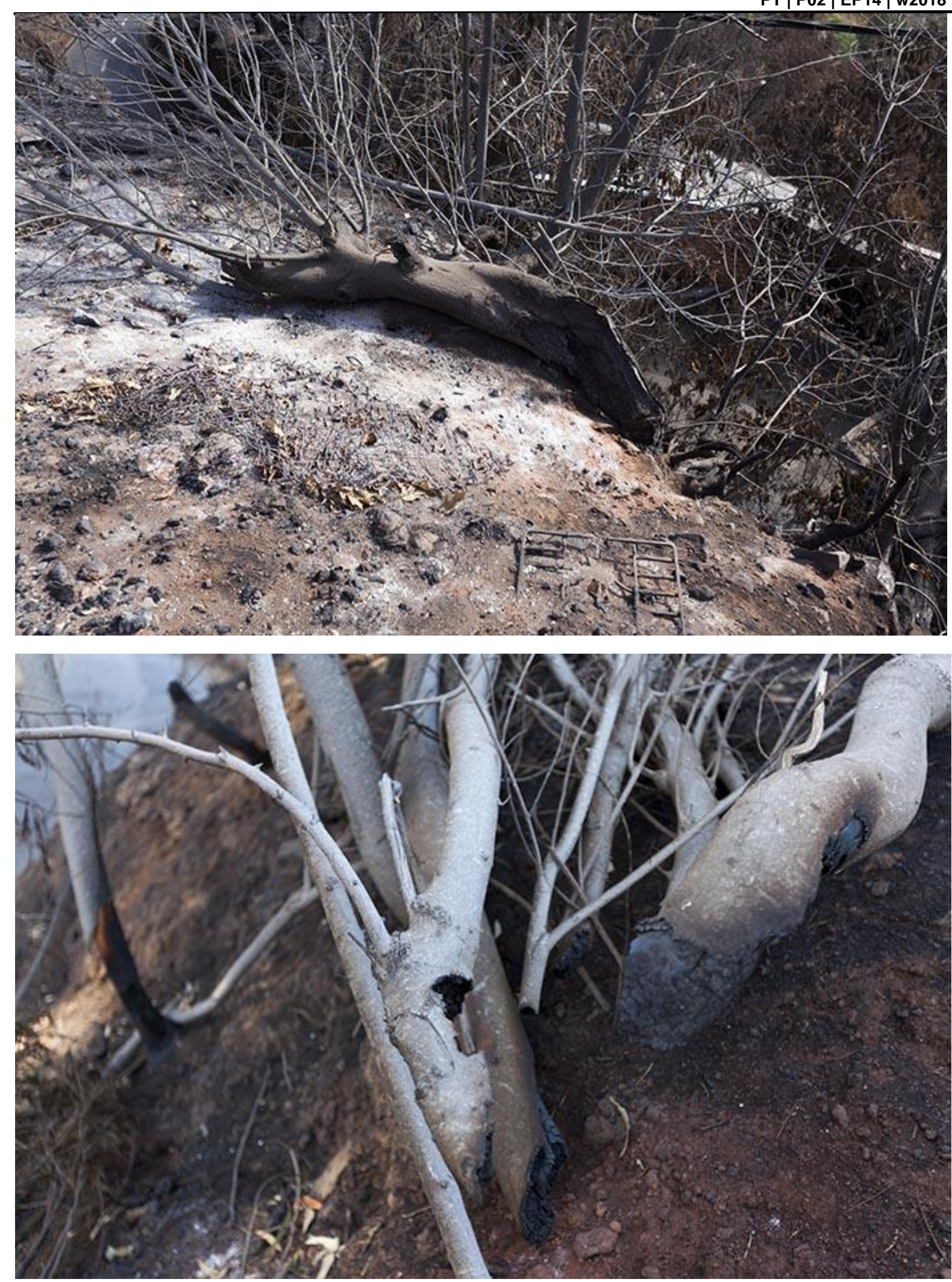

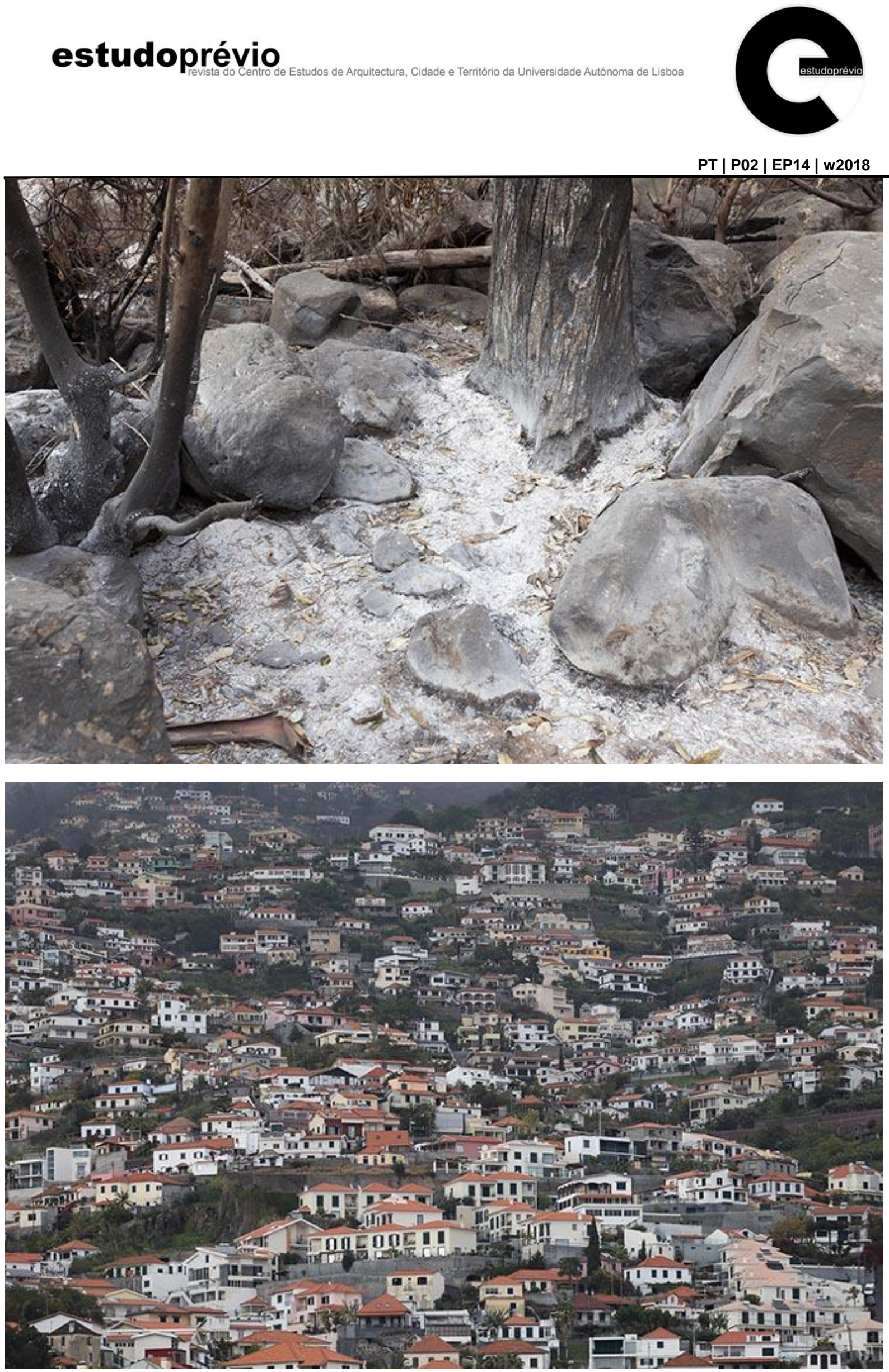


\section{Biografia:}

Duarte Belo (Lisboa, 1968).

Licenciado em Arquitectura (1991). Paralelamente à actividade inicial em Arquitectura, desenvolve projectos em Fotografia. Expõe individualmente desde 1989, tendo já participado em numerosas exposições individuais. Está representado em diversas colecções públicas e privadas, em Portugal e no estrangeiro. Já desenvolveu a actividade de docência e participa regularmente em seminários, congressos e mesas redondas.

Da obra publicada poderíamos destacar Orlando Ribeiro - Seguido de uma viagem breve à Serra da Estrela (1999); Ruy Belo - Coisas de Silêncio (2000); O Vento Sobre a Terra — apontamentos de viagens (2002); À Superfície do Tempo - Viagem à Amazónia (2002); Território em Espera (2005); Geografia do Caos (2005); Terras Templárias de Idanha (2006); Olívia e Joaquim - Doces de Santa Clara em Vila do Conde (2007); Fogo Frio - O Vulcão dos Capelinhos (2008); Comboios de Livros (2009); Desenha, produz e fotografa as ilustrações do conto O Príncipe-Urso Doce de Laranja (2009); Cidade do Mais Antigo Nome (2010).

De uma obra documental extensa, centrada no levantamento fotográfico da paisagem e das formas de ocupação do território, são de destacar as obras Portugal — O Sabor da Terra (1997) e Portugal Património (2007-2008). 